\title{
Upcoming Euroson Schools
}
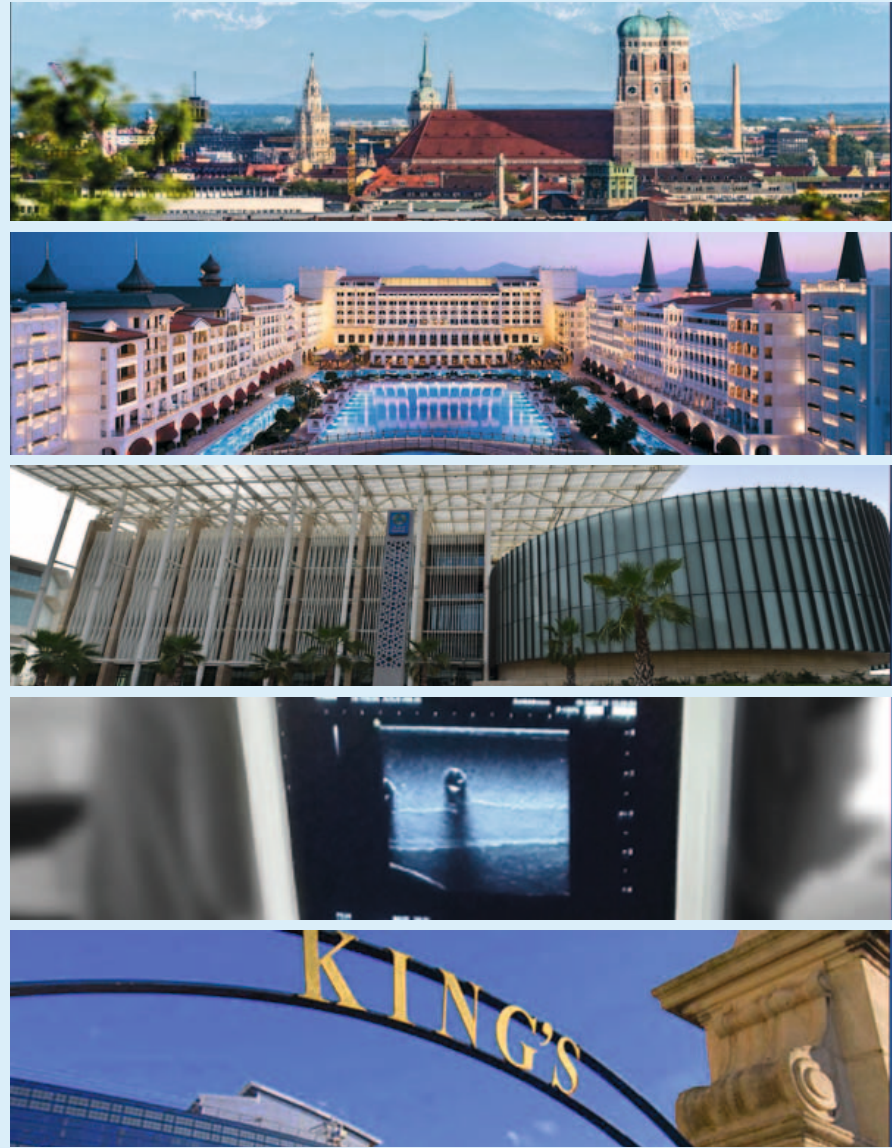

EUROSON SCHOOL: INTERNATIONAL COURSE IN CONTRAST ENHANCED ULTRASOUND, HEPATIC AND EXTRAHEPATIC INDICATIONS

Location: Munich, Germany

October 13-16, 2021

VIEW HERE

EUROSON SCHOOL: Basic Ultrasound Course

Location: Antalya, Turkey

October 24-26, 2021

VIEW HERE

EUROSON SCHOOL: 7th Qatar Musculoskeletal Ultrasound Course

Basic and Intermediate level

Location: Itgan (Simulation Center) - Live \& Hybrid (Virtual)

November 25-28, 2021

VIEW HERE

EUROSON SCHOOL: Interventional Ultrasound

Location: Berlin, Germany

Format: Lectures \& Hands On Training

April 4-6, 2022

VIEW HERE

EUROSON SCHOOL: London CEUS Course

Location: King's College Hospital, London

June 20-21, 2022

VIEW HERE 